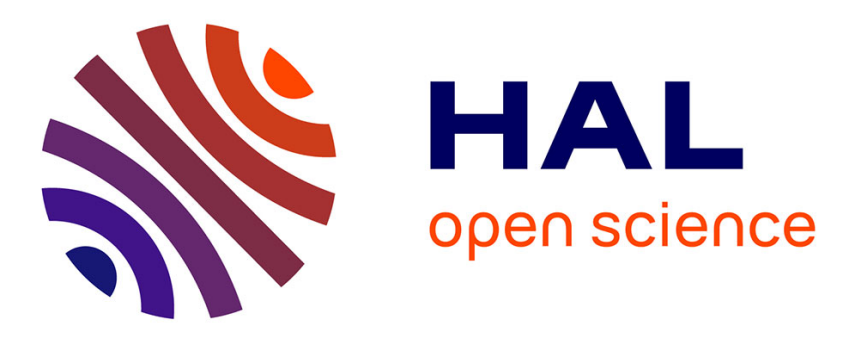

\title{
Intraspecific maternal competition induces summer diapause in insect parasitoids
}

Kévin Tougeron, George Hraoui, Cécile Le Lann, Joan van Baaren, Jacques Brodeur

\section{- To cite this version:}

Kévin Tougeron, George Hraoui, Cécile Le Lann, Joan van Baaren, Jacques Brodeur. Intraspecific maternal competition induces summer diapause in insect parasitoids. Insect Science, 2018, 25 (6), pp.1080-1088. 10.1111/1744-7917.12491 . hal-01810996

\section{HAL Id: hal-01810996 \\ https://hal-univ-rennes1.archives-ouvertes.fr/hal-01810996}

Submitted on 8 Jun 2018

HAL is a multi-disciplinary open access archive for the deposit and dissemination of scientific research documents, whether they are published or not. The documents may come from teaching and research institutions in France or abroad, or from public or private research centers.
L'archive ouverte pluridisciplinaire HAL, est destinée au dépôt et à la diffusion de documents scientifiques de niveau recherche, publiés ou non, émanant des établissements d'enseignement et de recherche français ou étrangers, des laboratoires publics ou privés. 
Author running title: $K$. Tougeron et al.

Title running head: Competition-induced diapause

Correspondence: Kevin Tougeron, UMR-CNRS 6553 Ecobio, Université de Rennes 1263

avenue du général Leclerc, 35042, Rennes, France. Orcid 0000-0003-4897-3787; e-mail:

tougeron.kevin@gmail.com

ORIGINAL ARTICLE

Intraspecific maternal competition induces summer diapause in insect parasitoids

Kevin Tougeron ${ }^{1,2,3}$, George Hraoui ${ }^{3}$, Cécile Le Lann $^{1,2}$, Joan van Baaren ${ }^{1,2}$ and Jacques Brodeur $^{3}$

${ }^{1}$ UMR-CNRS 6553 Ecobio, Université de Rennes 1, 263 avenue du général Leclerc, 35042, Rennes, France; ${ }^{2}$ Université Bretagne Loire, Cité Internationale, 1 place Paul Ricœur, 35044 Rennes, France and ${ }^{3}$ Institut de Recherche en Biologie Végétale, Département de sciences biologiques, Université de Montréal, 4101 rue Sherbrooke Est, Montréal, QC H1X 2B2, Canada,

Abstract Organisms often live in unpredictable environments and have to adopt life history strategies that optimize their fitness under these conditions. According to bet-hedging theory, individuals can reduce variation in fitness outcomes by investing in different strategies at the same time. For arthropods, facultative summer diapause enables survival during dry and hot periods of the year, and can be triggered by a decrease in resource abundance. However, the 
effect of resource depletion on diapause induction has never been disentangled from the effect of the perception of the presence of competitors. Using two solitary parasitoid species of cereal aphids as a model system, Aphidius avenae (Haliday) and Aphidius rhopalosiphi (De Stefani-Perez) (Hymenoptera: Braconidae), we tested whether (i) low absolute host density and/or (ii) high levels of parasitoid females' competition lead to maternal-induced summer diapause in parasitoid offspring. Under summer-like climatic conditions, emerging parasitoid females were (i) reared alone and exposed to different host densities (from 5 to 130 aphids), or (ii) reared together with competing females (from 2 to 20 females) and then exposed individually to 50 aphids. For both parasitoid species, low aphid densities did not induce summer diapause. However, the incidence of summer diapause increased up to a maximum of $11 \%$ with increasing levels of competition experienced by female parasitoids. More than $60 \%$ of the females produced both diapausing and non-diapausing offspring after being kept at the two highest competition densities. Such a "spreading-the-risk" strategy has likely evolved to optimize parasitoid fitness by preventing the following generation from exposure to low populations of suitable hosts and high mortality from superparasitism. These results provide the first experimental evidence of direct maternal competition-induced diapause in insects, and may change the way we apprehend the evolution of arthropod seasonal ecology, by considering intraspecific competition.

Key words aestivation; bet-hedging; host density; intraspecific competition; superparasitism

\section{Introduction}

Phenotypic plasticity allows a given genotype to produce a range of phenotypes in response to variable environmental conditions (Auld et al., 2010). For example, alternative lifehistories can arise from maternal effects (i.e. transgenerational plasticity), whereby the proportion of individuals expressing a given phenotype depends on the conditions 
experienced by the preceding generation (Mousseau \& Dingle, 1991). In insects, facultative diapause, a period of deferred development, can be induced by environmental cues perceived either by the diapausing individual or by its mother (Saunders, 1965; Tauber et al., 1986; Brodeur \& McNeil, 1989). In the latter case, the female can change carbohydrates and polyols contents of the egg through hormonal regulation which acts on the egg's development (Yamashita et al., 2001; Denlinger, 2002). Such 'anticipatory' maternal effects allow the mother to alter the phenotype of her offspring to increase their survival in the future environment by buffering against anticipated environmental stressors (Burgess \& Marshall, 2014). However, when a female cannot exactly assess which phenotype would be favored in the future environment, she may produce a range of offspring phenotypes to optimize her fitness (i.e. she "hedges her bets"). The proportion of each offspring phenotype may be adjusted to the probability of encountering a given environment, when biotic or abiotic cues make it partially predictable (Hopper, 1999; Menu et al., 2000; Marshall \& Uller, 2007).

Summer diapause is a phase of dormancy that is followed by an active phase in fall and occurs either at the same developmental stage as winter diapause, or at a different one (Masaki, 1980). Summer diapause should be distinguished from aestivation which is a form of dormancy mostly expressed in tropical insects during the dry season (Navas \& Carvalho, 2010; Denlinger \& Armbruster, 2014). Although overlooked, summer diapause is likely to be as widespread as winter diapause among insects (Masaki, 1980), and has been observed in few hymenopterous parasitoid species from temperate regions (He et al., 2010, and references therein). Whereas the developmental, physiological and hormonal syndrome associated with summer diapause is quite similar to winter diapause syndrome (i.e. metabolic depression, developmental arrest and increasing resistance to adverse conditions) (Masaki, 1980; Denlinger \& Armbruster, 2014), there is still a black-box in insect ecology and physiology concerning diapause induction, maintenance and termination stimuli (Koštál, 
2006). It has been shown that summer diapause is predominantly induced by overcrowding on a resource patch, by a decrease in food resource availability and/or by dry and warm environmental conditions (Masaki, 1980; Tauber et al., 1998). In the leaf-curling midge parasitoid Platygaster demades Walker (Hymenoptera: Platygastridae), there is a bet-hedging strategy on embryonic summer diapause levels and duration to match expected periods of host-shortage, thus avoiding fitness impairment and asynchronism with hosts (He et al., 2010). In addition to limited food resources, competition avoidance has been proposed as a factor selecting for diapause evolution in insects because competition may also lead to a reduction in resource availability (Danks, 1987; Lalonde, 2004). Induction of diapause through competition (i.e. due to overcrowding on a resource patch) has been reported in rotifers (Gilbert, 2004) and some insects among the Lepidoptera, Hemiptera, Coleoptera and Hymenoptera (Brown et al., 1979; Hagstrum \& Silhacek, 1980; Harada \& Spence, 2000; He et al., 2010; Togashi, 2016). However, to our knowledge, the influence of resource scarcity due to competition was never disentangled from the influence of competition perception by itself on diapause induction, and increasing maternal competition was never shown to induce diapause in their offspring. Separating these effects would bring new evolutionary insights on intraspecific interactions theories, on arthropods' seasonal ecology in response to varying environments and in the face of climate change, as well as on still overlooked token stimuli that control dormancy in insects.

For insect parasitoids, the quality of their environment depends on both the suitability and abundance of hosts which vary throughout the seasons (Vercken et al., 2015). Parasitoids have evolved behavioral responses to cope with both intra- and interspecific competition for hosts which can be used as a proxy for measuring resource availability and the risk of superparasitism (Boivin \& Brodeur, 2006; Cusumano et al., 2016). Superparasitism is repeated parasitism of a host by female parasitoids of the same species. It is typically 
deleterious for solitary parasitoids (van Alphen \& Visser, 1990; Harvey et al., 2013) and increases with the level of competition between females in a population. Competition should thus be avoided in order to reduce the probability of both resource (host) scarcity and superparasitism. In aphid parasitoids, competing females have the capacity to modify their foraging behaviour in response to the presence of competitors, mostly detected through visual and chemical cues (Mackauer, 1990; Barrette et al., 2009; van Baaren et al., 2009). For instance, Aphidius ervi Haliday (Hymenoptera: Braconidae) increase their patch residence time when exploiting an aphid colony in presence of competitors (direct perception of competition) or foraging on a patch previously exploited by competitors (indirect perception of competition) (Le Lann et al., 2011a).

We aimed to disentangle the effect of low host availability from the effect of maternal perceived competition (i.e. low relative host availability) on the incidence of summer diapause. We also measured the duration of summer diapause, which remains un-documented in most parasitoid species. We conducted experiments under laboratory conditions using two sympatric parasitoid species of the grain aphid Sitobion avenae (Fabricius) (Hemiptera: Aphididae); Aphidius avenae (Haliday) and Aphidius rhopalosiphi (De Stefani-Perez) (Hymenoptera: Braconidae). In cereal fields, these parasitoid species experience rapid decrease in host availability in summer (Rabasse et al., 1983), especially because host-plants are drying and aphids are subject to deleterious heat shocks (Alford et al., 2012). Previously observed levels of summer diapause were relatively low in A. avenae and A. rhopalosiphi under natural conditions ( $<5 \%$ of the population), when aphid abundance was low in the field (Starý, 1966; Krespi et al., 1997). The cues responsible for triggering summer diapause in these species were not identified. In cereal fields of Western France, A. avenae is most abundant from spring to fall while A. rhopalosiphi presents higher abundance from autumn to spring (Krespi, 1990; Andrade et al., 2016; Tougeron et al., 2016b). The two species differ in 
their capacity to enter winter diapause; A. rhopalosiphi does not produce diapausing individuals whereas A. avenae enters winter diapause at low levels (Tougeron et al., 2016a). Aphidius avenae is about $1{ }^{\circ} \mathrm{C}$ more resistant to high temperatures than A. rhopalosiphi (Le Lann et al., 2011b) which may imply lower summer diapause incidence in the former species. Hence, the following hypotheses were tested: the incidence of summer diapause in parasitoid offspring is higher (i) when females encounter low aphid densities, (ii) when females experience high levels of conspecific competition, and (iii) in A. rhopalosiphi than in $A$. avenae, considering differences in their heat tolerance and seasonal occurrence.

\section{Material and methods}

\section{Biological material}

Aphidius avenae and A. rhopalosiphi were collected from cereal fields in Western France (Long Term Ecological Research area ZA Armorique, $48^{\circ} 08^{\prime} \mathrm{N}, 1^{\circ} 80^{\prime} \mathrm{W}$ ) in 2014 and 2015 (details in Tougeron et al., 2016a) and have since been reared on a colony of the grain aphid S. avenae established from a single female collected at Le Rheu, France, in 1990. Parasitoids were reared at $20^{\circ} \mathrm{C}, 70 \%$ relative humidity (RH), and under $16 \mathrm{~h}: 8 \mathrm{~h}$ light: dark (LD) photoperiod while aphids were reared at $24^{\circ} \mathrm{C}, 55 \% \mathrm{RH}$, and $16 \mathrm{~h}: 8 \mathrm{~h} \mathrm{LD}$ on winter wheat (Triticum aestivum var. Mégantic).

\section{General experimental conditions}

Experiments were conducted at $24^{\circ} \mathrm{C}, 55 \% \mathrm{RH}$, and $16 \mathrm{~h}: 8 \mathrm{~h} \mathrm{LD}$. These conditions simulate those that are typically encountered in the study area when aphid parasitoid summer diapause is assumed to occur, between 20th June and 31st August (Krespi et al., 1997; Météo France, 2015). Ten days prior to a test, apterous parthenogenetic aphids were placed on sprouted wheat (about $2 \mathrm{~cm}$ high) in experimental arenas (plastic pots $\Phi 10 \mathrm{~cm}$ ) to produce 
aphid cohorts of 2 nd or 3 rd instar larvae. When necessary, aphids of the same age from the aphid colony were added to the infested wheat plants to reach the required density.

Last larval instars of Aphidiinae parasitoids make a cocoon and pupate inside the dead aphid host; the resulting structure is called a 'mummy'. Aphid mummies were taken from the parasitoid colonies, isolated in small gelatin capsules $(\Phi 5 \mathrm{~mm})$, and acclimated to the experimental abiotic conditions until adult emergence (3 to 5 days). Following emergence, each parasitoid female was placed in the presence of 2 males for mating and provided a honey solution ( $70 \%$ dilution) for $36 \mathrm{~h}$. This duration allows females to reach their maximum egg-load (Le Lann et al., 2012). Parasitoid females were then held along with aphids and honey in the experimental arenas for 48 hours, following the two protocols described below. Mummy formation in the arenas was checked every day, beginning one week after oviposition. Mummies were kept individually in gelatin capsules at $20^{\circ} \mathrm{C}$ and adult emergence was checked daily. Twenty days after the first adult emergence within a single female offspring, the remaining mummies in the cohort were dissected, except for the diapause duration experiment (see below), and the content was recorded as being a dead individual or a diapausing golden-yellow prepupa (Tougeron et al., 2016a).

\section{Effect of host density on offspring diapause incidence}

To test the effects of host density on summer diapause incidence, we exposed parasitoids to the following host densities: 5, 20, 50, 65 and 130 aphids. These densities are encountered in the fields on wheat shoots (Roschewitz et al., 2005) and encompass the realized fecundities for 48 hours of both parasitoid species. Aphidius avenae and A. rhopalosiphi are able to produce about 62 and 31 mummies in two days, respectively (Le Lann et al., 2012). Naive mated females (i.e. without oviposition experience or contact with other females) were individually introduced into experimental arenas to parasitize aphids. This experiment was 
replicated using four different females for each parasitoid species and aphid density modality (for a total of 20 females per species).

\section{Effect of competition between females on offspring diapause incidence}

To test the effect of competition among parasitoid females on summer diapause incidence, mated females were placed in plastic tubes $(\Phi=4 \mathrm{~cm}, \mathrm{~L}=9 \mathrm{~cm})$ for 48 hours at the following densities: 2, 5, 10 and 20 females. These densities were chosen to represent the range of direct competition a female might experience in either natural (as indicated by natural parasitism rates, Roschewitz et al., 2005) or laboratory rearing settings; with two and twenty females competing being highly credible in the field and in mass-rearing condition, respectively. Females were individually introduced in an experimental arena containing 50 aphids. This experiment was replicated using fifteen different females for each parasitoid species and competition treatment (for a total of 60 females per species).

\section{Diapause duration in the offspring after mothers' competition experience}

To measure the duration of summer diapause, four additional females of each parasitoid species from the 20-females-competition treatment were allowed to parasitize 50 aphids each. Following parasitoid development, mummies were placed in gelatin capsules and parasitoid emergence was checked every day. Data are accurate to \pm 2 days since parasitoids that emerged during the weekend were pooled with those emerging on Monday. Parasitoids with a delay of emergence $>20$ days after first adult emergence were considered to be in diapause. This 20-days threshold was determined a priori since egg-to-adult development in nondiapausing Aphidius sp. usually lasts from 12 to 16 days at $20^{\circ} \mathrm{C}$ (Zamani et al., 2007), and confirmed a posteriori following the distribution of emergence data. The remaining 
mummies were dissected 30 days after no emergence had been recorded in a given cohort to determine the status (dead or in diapause) of the parasitoid.

\section{Statistical analyses}

No diapausing individuals were produced following the host density experiment (see results section) and therefore no statistical analysis was conducted on this dataset. To test for the effects of female competition (categorical effect), Generalized Linear Models (GLMs) with a quasi-binomial error distribution (to account for overdispersion) and a logit-link function were fitted to the data separately for each parasitoid species. The response variable was the number of diapausing and non-diapausing individuals, including dead ones, for each replicate (ovipositing female). Another GLM with a quasi-binomial error distribution was fitted to the data to test for differences in diapause induction between parasitoid species, competition treatment as well as their interaction. The significance of each factor was tested by implementing an iterative procedure with the 'Anova' function from the package car, using $F$-tests for quasi-binomial data (Fox \& Weisberg, 2011). Differences between competition levels were compared with Tukey Contrasts (Hothorn et al., 2008). Data for diapause duration within a species was pooled and thus was not compared among the offspring of different females. Statistical analyses were carried out with $R$ software (R Development Core Team, 2015).

\section{Results}

Effect of host density on offspring diapause incidence

Aphid density (5, 20, 50, 65 and 130 individuals) had no effect on summer diapause expression; none of the mummies contained diapausing individuals for either $A$. avenae $(n=$ 219 total mummies formed) or A. rhopalosiphi $(n=205)$. Parasitism rates (i.e. number of 
mummies formed / total number of aphids proposed to parasitoids) varied between aphid density treatments but were constant within a given density. They ranged between $80 \%$ and $100 \%$ depending on the female parasitoid at the density of 5 aphids and between $10 \%$ and $30 \%$ at the density of 130 aphids.

\section{Effect of competition between females on offspring diapause incidence}

Increasing competition between females led to increasing summer diapause induction in their offspring for both $A$. avenae (GLM, $F=76.8$, df $=3, P<0.001, n=1327$ ) and $A$. rhopalosiphi $(F=89.2$, df $=3, P<0.001, n=1174)$ (Fig. 1). In the competition treatment of 20 females, diapause incidence reached maximums of $11.22 \pm 1.5 \%$ and $9.92 \pm 1.3 \%($ mean \pm SE) for $A$. avenae and $A$. rhopalosiphi, respectively. The 20 -female competition treatment showed significantly higher proportions of parasitoids in summer diapause than the competition treatment of 10 females in A. avenae (Tukey Contrasts; $z=3.73, P<0.005$ ) but not in A. rhopalosiphi $(z=1.10, P=0.69)$. There was no summer diapause in the other two competition treatments ( 2 and 5 females) for either parasitoid species. There was no significant difference in summer diapause incidence between species (GLM, $F=0.75$, $\mathrm{df}=1$, $P=0.39)$ and no significant interaction between species and competition level $(F=2.28, \mathrm{df}=$ $3, P=0.08)$.

Not all females produced diapausing offspring; in the competition treatment with 20 females, for both parasitoid species, $93.3 \%$ of the tested females (14 out of 15) produced a minimum of one offspring in diapause. In the competition treatment with 10 females, the proportion of females inducing summer diapause in their offspring decreased to $60 \%$ (9 out of 15 ) and $86.7 \%$ (13 out of 15 ) for A. avenae and A. rhopalosiphi, respectively. Moreover, there was high variability in the diapause incidence within each female offspring for females that produced diapausing individuals; from $2.9 \%$ to $20 \%$ in $A$. avenae and from $4.8 \%$ to $20 \%$ 
in A. rhopalosiphi (in the 20 -female competition treatment for both species). In the 10 -female competition treatment this proportion ranged from $2.6 \%$ to $14.3 \%$ in $A$. avenae and from $3.0 \%$ to $20 \%$ in A. rhopalosiphi.

\section{Diapause duration in the offspring after mothers' competition experience}

Most parasitoids did not enter diapause, emerging from 12 to 27 days after oviposition $(80.5 \%, n=62$ for $A$. avenae; $75 \%, n=54$ for $A$. rhopalosiphi). Nine $(11.7 \%)$ A. avenae and seven (9.7\%) A. rhopalosiphi individuals emerged more than 32 days after oviposition (i.e. more than 20 days after the first emergence in their cohort) and were considered to be in summer diapause. The mean summer diapause duration was similar for both parasitoid species (A. avenae, $55.6 \pm 5.2$ days; A. rhopalosiphi, $54.7 \pm 4.3$ days), although emergences spread over a longer period in A. avenae (Fig. 2). All remaining mummies dissected 113 days after oviposition (last adult emergence occurred at day 83 after oviposition +30 days without any emergence) contained dead, non-diapausing individuals (15 adults and 2 pupae).

\section{Discussion}

In addition to its other functions, diapause allows species exploiting the same ecological niche to avoid competition (Danks, 1987; Alekseev \& Starobogatov, 1996; Tauber et al., 1998; Lalonde, 2004). Although competition avoidance has been invoked as a potential biotic factor selecting for the evolution of diapause (Danks, 1987), perception of competition has not been identified as a cue per se for summer or winter diapause induction in insects probably because it has never been decoupled from the influence of resource scarcity due to overcrowding. We report no effect of resource scarcity (host density), but we did observe a clear effect of increasing maternal competition on summer diapause induction in the progeny of two Aphidius parasitoids. This is the first evidence, to our knowledge, of maternal 
perception of competition for resources being identified as a biotic cue for summer diapause induction in insects. Summer diapause was triggered by the same cues and expressed in a similar way (i.e. incidence and duration) in both A. avenae and A. rhopalosiphi. Summer diapause led to a developmental arrest occurring at the same developmental stage (prepupa) as for winter diapause (Brodeur and McNeil, 1989; Tougeron et al., 2016a). Although only expressed in a part of the population, summer diapause can have important consequences for parasitoids' life-cycle, population dynamics and interactions with their hosts.

Although the syndrome associated with summer and winter diapause is similar (Masaki, 1980; Denlinger \& Armbruster, 2014), their inducing environmental cues differ as suggested by Masaki (1980), Tauber et al. (1986) and Koštál (2006), mostly because summer diapause serves different ecological functions from winter diapause. Maternal effects on winter diapause expression in Aphidius sp. can be significant but remains marginal compared to other environmental stimuli, mainly photoperiod and temperature (Brodeur \& McNeil, 1989; Langer \& Hance, 2000). In the genus Aphidius, conditions directly encountered by the early sensitive stage (egg, young larva) represent the main cues initiating diapause (Brodeur and McNeil, 1989; Tougeron et al., 2016a). In contrast, for other parasitoid species such as Nasonia vitripennis, winter diapause is triggered only by maternal environmental perception (Saunders, 1965) and is linked to seasonal patterns of host availability (Saunders et al., 1970). In contrast to winter diapause, our results suggest that summer diapause has a strong maternal component in Aphidius species.

Summer diapause induction in Aphidius offspring appears to arise from the perception of direct conspecific competition among females, when no hosts are available. This perception may be a proxy for measuring the risk of both host shortage and superparasitism in the future offspring environment. Our results also suggest that solitary parasitoids may respond differently to the risk of self-superparasitism (i.e. by a single female; host-density 
experiment) which can be neutral or beneficial (van Alphen \& Visser, 1990), than to the risk of conspecific superparasitism (competition experiment), which is typically detrimental. Indeed, in the experiment on host density, transgenerational diapause induction was not observed, even when only 5 aphids were offered for 48 hours, which strengthens the idea that increasing competition alone induces summer diapause.

Not all parasitoid females produced diapausing offspring, and individual mothers that did lay diapausing offspring did so in only a subset of their progeny. This variability could be explained either by differing sensitivity to competition among mothers (i.e. high genetic polymorphism in the population) or high degrees of plasticity in parasitoid females. Because the offspring's environment cannot be fully predicted from the conditions experienced by the mother, evolution can select for maternal genotypes that produce both diapausing and nondiapausing offspring, and modify the frequency of each phenotype regarding relevant environmental cues (Hopper, 1999), such as the level of competition for host resources. In this context, summer diapause expression induced by parasitoid mothers could be viewed as a type of 'conditional diversified bet-hedging' strategy (sensu de Jong et al., 2011). In the light of the above, we hypothesize that risks may be spread both among mothers at the population scale (not all mothers produced diapausing offspring) and at the progeny scale (individual mothers induced diapause in only a part of their offspring).

The highest female density we tested $(n=20)$ is likely to occur in laboratory or industrial mass-rearing but are less credible in field conditions. In cereal fields, Aphidius sp. abundances per aphid patch are relatively low, greatly vary between years (Roschewitz et al., 2005), and high levels of direct intraspecific competition may rarely occur among solitary parasitoids (Vollhardt et al., 2008; Wajnberg et al., 2008). It may however occur for interspecific competition (e.g. host-patches exploited by different parasitoid females at the same time leading to high multiparasitism levels) or in other parasitoid species (e.g. 
gregarious parasitoids). The incidence of summer diapause induced by maternal competition under natural conditions nevertheless remains unknown. Our results are likely to translate to other parasitoids, including those released in inundative biological control programs. In the context of biological control, improving knowledge of factors inducing diapause is also of great importance if we aim at improving conditions of mass-rearing (Boivin et al., 2012).

The emergence of $A$. avenae and $A$. rhopalosiphi individuals following summer diapause was spread over a long period of time (up to 11 weeks after oviposition). This pattern could represent a form of temporal risk-spreading to avoid parasitoid overcrowding on a resource patch and would also be beneficial when extreme climatic events could impair parasitoid survival. However, summer diapause duration, maintenance and termination mechanisms remain to be measured in field conditions. This pattern contrasts with other aphid parasitoid species, such as Aphidius nigripes (Ashmead), in which spring emergence after winter diapause is highly synchronized and occurs within three weeks (Brodeur \& McNeil, 1994). We also showed that development from egg to adult emergence extended to a maximum of 83 days for parasitoids entering summer diapause. This is substantially less than winter diapause, which lasts for several months in overwintering aphid parasitoids from temperate areas (Brodeur \& McNeil, 1994). These findings strengthen the idea that summer diapause has evolved in insects to cope with short-term deleterious conditions such as high competition for hosts - which are ephemeral resources - rather than predictive, long-term environmental fluctuations.

Parasitoid pupae developing inside the aphid mummy are highly vulnerable to natural enemies and adverse climatic conditions (Brodeur \& Rosenheim, 2000). The optimal proportion of offspring entering summer diapause might be selected to balance risks of competition for hosts and mortality from, disease, extreme climatic events, predation or hyperparasitism (which levels can be high at the end of the summer, Holler et al., 1993). 
There are, for instance, a few examples of predator-induced diapause in arthropods (Slusarczyk, 1995; Kroon et al., 2008). Rausher (1986) also argued that a female butterfly’s decision to induce diapause or not in a given proportion of its offspring may also depend on the 'decision' taken by its competitors. In this regard, intra- and interspecific interactions between insects as well as predation and hyperparasitism levels must be considered in future research when studying summer diapause as a density-dependent process. However, the underlying ecological processes behind summer diapause induction and duration are poorly understood for insects from temperate regions and substantially more knowledge is needed concerning the multiple biotic and abiotic factors other than competition, and their interactions, that modulate summer diapause.

\section{Acknowledgments}

KT was supported by the French Région Bretagne and the Canada Research Chair in Biological Control awarded to JB. The study was supported by the LTER France Zone Atelier Armorique. We thank P. Abram for insightful comments on an earlier version of the manuscript and for revising the use of English, three anonymous reviewers for helpful comments and J. Doyon and M. Gaudreau for technical support.

Disclosure

The authors declare no conflict of interest.

\section{Author contributions}

KT, CLL, JVB and JB conceived the experiments. KT and GH performed the experiments. KT analyzed the data and wrote the manuscript. All co-authors contributed substantially to revisions.

\section{References}


Alekseev, V.R. and Starobogatov, Y.I. (1996) Types of diapause in Crustacea: definitions, distribution, evolution. Hydrobiologia, 320, 15-26.

Alford, L., Blackburn, T.M. and Bale, J.S. (2012) Effect of latitude and acclimation on the lethal temperatures of the peach-potato aphid Myzus persicae. Agricultural and Forest Entomology, 14, 69-79.

Andrade, T.O., Krespi, L., Bonnardot, V., van Baaren, J. and Outreman, Y. (2016) Impact of change in winter strategy of one parasitoid species on the diversity and function of a guild of parasitoids. Oecologia, 180, 877-888.

Auld, J.R., Agrawal, A.A. and Relyea, R.A. (2010) Re-evaluating the costs and limits of adaptive phenotypic plasticity. Proceedings of the Royal Society B: Biological Sciences, 277, 503-511.

Barrette, M., Wu, G.M., Brodeur, J., Giraldeau, L.A. and Boivin, G. (2009) Testing competing measures of profitability for mobile resources. Oecologia, 158, 757-764.

Boivin, G. and Brodeur, J. (2006) Intra- and interspecific interactions among parasitoids: mechanisms, outcomes and biological control. Trophic and Guild in Biological Interactions Control. (eds. J. Brodeur \& G. Boivin ), pp. 123-144. Springer Netherlands, Dordrecht.

Boivin, G., Hance, T. and Brodeur, J. (2012) Aphid parasitoids in biological control. Canadian Journal of Plant Science, 92, 1-12. Brodeur, J. and McNeil, J.N. (1989) Biotic and abiotic factors involved in diapause induction of the parasitoid, Aphidius nigripes (Hymenoptera: Aphidiidae). Journal of insect Physiology, 35, 969-974.

Brodeur, J. and McNeil, J.N. (1994) Seasonal Ecology of Aphidius nigripes (Hymenoptera: Aphidiidae), a parasitoid of Macrosiphum euphorbiae (Homoptera: Aphididae). Environmental Entomology, 23, 292-298. 
Brodeur, J. and Rosenheim, J.A. (2000) Intraguild interactions in aphid parasitoids. Entomologia Experimentalis et Applicata, 97, 93-108.

Brown, G.C., Berryman, A.A. and Bogyo, T.P. (1979) Density-dependent induction of diapause in the codling moth, Laspeyresia pomonella (Lepidoptera: Olethreutidae). The Canadian Entomologist, 111, 431-433.

Burgess, S.C. and Marshall, D.J. (2014) Adaptive parental effects: the importance of estimating environmental predictability and offspring fitness appropriately. Oikos, 123, 769-776. Cusumano, A., Peri, E. and Colazza, S. (2016) Interspecific competition/facilitation among insect parasitoids. Current Opinion in Insect Science, $14,12-16$.

Danks, H.V. (1987) Insect Dormancy: an Ecological Perspective. Biological Survey of Canada (Terrestrial Arthropods). Entomological Society of Canada. 439 pp.

de Jong, I.G., Haccou, P. and Kuipers, O.P. (2011) Bet hedging or not? A guide to proper classification of microbial survival strategies. BioEssays, 33, 215-223.

Denlinger, D.L. (2002) Regulation of diapause. Annual Review of Entomology, 47, 93-122.

Denlinger, D.L. and Armbruster, P.A. (2014) Mosquito diapause. Annual Review of Entomology, 59, 73-93.

Fox, J. and Weisberg, H.S. (2011) An R Companion to Applied Regression, 2nd edn. Sage, Thousand Oaks, CA, USA. 472 pp.

Gilbert, J.J. (2004) Population density, sexual reproduction and diapause in monogonont rotifers: new data for Brachionus and a review. Journal of Limnology, 63, 32-36.

Hagstrum, D.W. and Silhacek, D.L. (1980) Diapause induction in Ephestia cautella: an interaction between genotype and crowding. Entomologia Experimentalis et Applicata, $28,29-37$. 
Harada, T. and Spence, J.R. (2000) Nymphal density and life histories of two water striders (Hemiptera: Gerridae). The Canadian Entomologist, 132, 353-363.

Harvey, J.A., Poelman, E.H. and Tanaka, T. (2013) Intrinsic inter- and intraspecific competition in parasitoid wasps. Annual Review of Entomology, 58, 333-351.

He, X.Z., Wang, Q., Walker, J.T.S., Rogers, D.J. and Lo, P.L. (2010) A sophisticated life history strategy in a parasitoid wasp: producing univoltine and multivoltine phenotypes in a local population. Biological Control, 54, 276-284.

Holler, C., Borgemeister, C., Haardt, H. and Powell, W. (1993) The relationship between primary parasitoids and hyperparasitoids of cereal aphids: an analysis of field data. The Journal of Animal Ecology, 62, 12

Hopper, K.R. (1999) Risk-spreading and bet-hedging in insect population biology. Annual Review of Entomology, 44, 535-560.

Hothorn, T., Bretz, F. and Westfall, P. (2008) Simultaneous inference in general parametric models. Biometrical Journal, 50, 346-363.

Koštál, V. (2006) Eco-physiological phases of insect diapause. Journal of Insect Physiology, $52,113-127$.

Krespi, L. (1990) Etude de la biocénose parasitaire des pucerons des céréales dans le bassin de Rennes: cas particulier d'Aphidius uzbekistanicus Luz. PhD dissertation. Université de Rennes 1, France.

Krespi, L., Dedryver, C.A., Creach, V., Rabasse, J.M., Ralec, A.L. and Nenon, J.P. (1997) Variability in the development of cereal aphid parasitoids and hyperparasitoids in oceanic regions as a response to climate and abundance of hosts. Population Ecology, $26,545-551$. 
Kroon, A., Veenendaal, R.L., Bruin, J., Egas, M. and Sabelis, M.W. (2008) "Sleeping with the enemy"- predator-induced diapause in a mite. Naturwissenschaften, 95, 11951198.

Lalonde, R.G. (2004) Some dynamical consequences of parasitoid diapause. Oikos, 107, $338-344$.

Langer, A. and Hance, T. (2000) Overwintering strategies and cold hardiness of two aphid parasitoid species (Hymenoptera: Braconidae: Aphidiinae). Journal of Insect Physiology, 46, 671-676.

Le Lann, C., Outreman, Y., van Alphen, J.J.M. and van Baaren, J. (2011a) First in, last out: asymmetric competition influences patch exploitation of a parasitoid. Behavioral Ecology, 22, 101-107.

Le Lann, C., Roux, O., Serain, N., van Alphen, J.J.M., Vernon, P. and van Baaren, J. (2011b) Thermal tolerance of sympatric hymenopteran parasitoid species: does it match seasonal activity? Physiological Entomology, 36, 21-28.

Le Lann, C., Visser, B., van Baaren, J., van Alphen, J.J.M. and Ellers, J. (2012) Comparing resource exploitation and allocation of two closely related aphid parasitoids sharing the same host. Evolutionary Ecology, 26, 79-94.

Mackauer, M. (1990) Host discrimination and larval competition in solitary endoparasitoids. Critical Issues in Biological Control. (eds. M., Mackauer, L.E., Ehler \& J., Roland). Intercept, Andover, UK.

Marshall, D.J. and Uller, T. (2007) When is a maternal effect adaptive? Oikos, 116,19571963.

Masaki, S. (1980) Summer diapause. Annual Review of Entomology, 25, 1-25.

Menu, F., Roebuck, J. and Viala, M. (2000) Bet - Hedging diapause strategies in stochastic environments. The American Naturalist, 155, 724-734. 
Mousseau, T.A. and Dingle, H. (1991) Maternal effects in insect life histories. Annual Review of Entomology, 36, 511-534.

Navas, C.A. and Carvalho, J.E. (2010) Aestivation, Molecular and Physiological Aspects. Springer Berlin Heidelberg, Berlin, Heidelberg. 262 pp.

R Development Core Team (2015) R: A language and environment for statistical computing. R Foundation for Statistical Computing, Vienna, Austria.

Rabasse, J.M., Dedryver, C.A., Gelle A and Tanguy, S. (1983) Biologie des pucerons des céréales dans l'Ouest de la France. III. Action des hyménoptères parasites sur les populations de Sitobion avenae F., Metopolophium dirhodum Wlk. et Rhopalosiphum padi L. Agronomie, 3, 779-790.

Rausher, M.D. (1986) Competition, frequency-dependent selection, and diapause in Battus philenor butterflies. The Florida Entomologist, 69, 63.

Roschewitz, I., Hücker, M., Tscharntke, T. and Thies, C. (2005) The influence of landscape context and farming practices on parasitism of cereal aphids. Agriculture, Ecosystems \& Environment, 108, 218-227.

Saunders, D., Sutton, D. and Jarvis, R. (1970) The effect of host species on diapause induction in Nasonia vitripennis. Journal of Insect Physiology, 16, 405-416.

Saunders, D.S. (1965) Larval diapause of maternal origin: induction of diapause in Nasonia vitripennis (Walk.) (Hymenoptera: Pteromalidae). Journal of Experimental Biology, $42,495-508$.

Slusarczyk, M. (1995) Predator-induced diapause in Daphnia. Ecology, 76, 1008-1013. Starý, P. (1966) The Aphidiidae of Italy (Hym., Ichneumonidae). Bollettino dell'Istituto di Entomologia della Universita degli Studi di Bologna, 28, 65-139.

Tauber, M.J., Tauber, C.A. and Masaki, S. (1986) Seasonal Adaptations of Insects. Oxford University Press, New York, USA. 426 pp. 
Tauber, M.J., Tauber, C.A., Nyrop, J.P. and Villani, M.G. (1998) Moisture, a vital but neglected factor in the seasonal ecology of insects: hypotheses and tests of mechanisms. Environmental Entomology, 27, 523-530.

Togashi, K. (2016) Effects of crowding on larval diapause and adult body size in Monochamus alternatus alternatus (Coleoptera: Cerambycidae). The Canadian Entomologist, 1-15. Tougeron, K., Le Lann, C., Brodeur, J. and Van Baaren, J. (2016a) Are parasitoids from mild winter areas losing their winter diapause? Oecologia, 183, 619-629.

Tougeron, K., van Baaren, J., Burel, F. and Alford, L. (2016b) Comparing thermal tolerance across contrasting landscapes: first steps towards understanding how landscape management could modify ectotherm thermal tolerance. Insect Conservation and Diversity, 9, 171-180.

van Alphen, J.J. and Visser, M.E. (1990) Superparasitism as an adaptive strategy for insect parasitoids. Annual Review of Entomology, 35, 59-79.

van Baaren, J., Le Lann, C., Pichenot, J., Pierre, J.S., Krespi, L. and Outreman, Y. (2009) How could host discrimination abilities influence the structure of a parasitoid community? Bulletin of Entomological Research, 99, 299.

Vercken, E., Fauvergue, X., Ris, N., Crochard, D. and Mailleret, L. (2015) Temporal autocorrelation in host density increases establishment success of parasitoids in an experimental system. Ecology and Evolution, 5, 2684-2693.

Vollhardt, I.M.G., Tscharntke, T., Wäckers, F.L., Bianchi, F.J.J.A. and Thies, C. (2008) Diversity of cereal aphid parasitoids in simple and complex landscapes. Agriculture, Ecosystems \& Environment, 126, 289-292. 
Wajnberg, E., Bernstein, C. and van Alphen, J. (2008) Behavioral Ecology of Insect Parasitoids: from Theoretical Approaches to Field Applications. Blackwell Pub, Malden, MA. 445 pp.

Yamashita O, Shiomi K, Ishida Y, Katagiri, N. and Niimi, T. (2001) Insights for future studies on embryonic diapause promoted by molecular analyses of diapause hormone and its action in Bombyx mori. Insect Timing: Circadian Rhythmicity to Seasonality (eds. D.L., Denlinger, J., Giebultowicz \& D., Saunders), pp. 145-153.

Zamani, A.A., Talebi, A., Fathipour, Y. and Baniameri, V. (2007) Effect of temperature on life history of Aphidius colemani and Aphidius matricariae (Hymenoptera: Braconidae), two parasitoids of Aphis gossypii and Myzus persicae (Homoptera: Aphididae). Environmental Entomology, 36, 263-271.

Manuscript received March 1, 2017

Final version received May 16, 2017

Accepted May 23, 2017

Fig. 1 Percentages ( \pm CI 95\%) of aphid mummies containing parasitoid prepupae in summer diapause in relation to the number of females in competition for Aphidius avenae (grey) and Aphidius rhopalosiphi (black). Different lower case letters (for A. avenae) and upper case letters (for A. rhopalosiphi) indicate significant differences between competition treatments (Tukey Contrasts). The total number of mummies is provided for each experimental condition. 


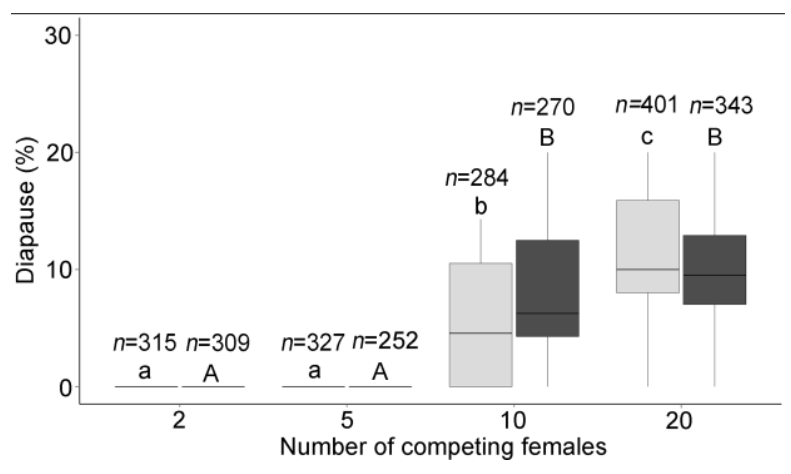

Fig. 2 Distribution over time of parasitoid (Aphidius avenae and Aphidius rhopalosiphi) emergence at $20^{\circ} \mathrm{C}$ for non-diapausing (grey bars) and diapausing (open bars) offspring developing in Sitobion avenae. For each parasitoid species, distributions represent pooled offspring data from four females. Vertical dashed lines represent the mean emergence time of parasitoids in summer diapause. Day zero is the day of oviposition.

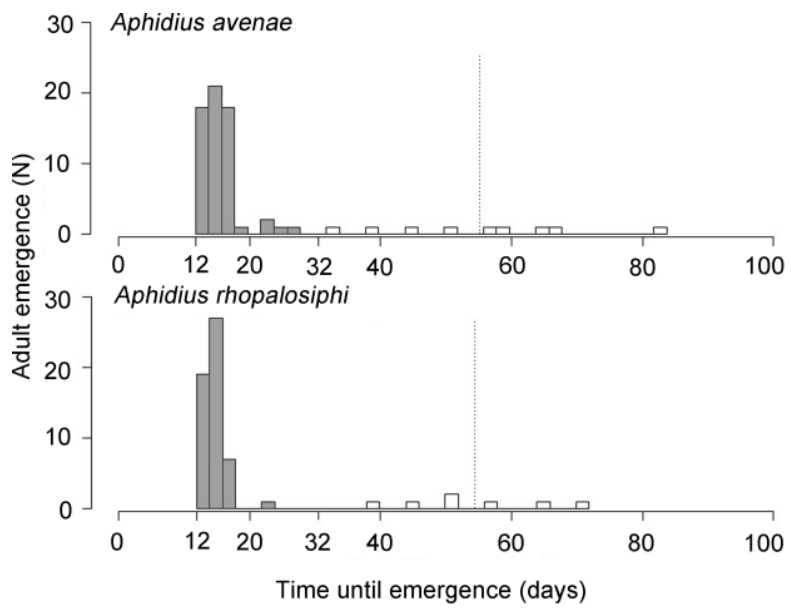

